\title{
Tetrahydropyrimidine Derivatives: A Potentiometric Study to Determine Dissociation Constant
}

\author{
Shipra Baluja*, Divyata Lava and Mehul Bhatt \\ Department of Chemistry,Saurashtra University, India
}

Received: April 03, 2018; Published: April 23, 2018

*Corresponding author: Physical Chemistry Laboratory, Department of Chemistry,Saurashtra University, Rajkot-360005 (Gujarat), India, Tel: 91-9558318625; Email: shipra_baluja@rediffmail.com

Abstract

The dissociation constants of some synthesized tetrahydropyrimidine derivatives were determined potentiometrically at ionic strength of $0.1 \mathrm{M}$ in N, N-dimethyl formamide: water 60:40 (v/v)system at 303.15 K. It is observed that dissociation constant depends on the substituent groups present in the compounds.

Keywords: Dissociation constant; Tetrahydropyrimidine; DMF; Enthalpy; Entropy; Gibb's Energy

\section{Introduction}

The acidic or basic strength of material can be highlighted by the dissociation constants. They are also known as acidity constant, ionization constant or formation constant.Dissociation constant is one of the important physicochemical parameter which provides critical information about drug properties such as solubility, lipophilicity, acidity [1], transport behaviour, bonding to receptors [2] and permeability [3]. Further, dissociation constant data is required for QSAR study [4,5]. Hence, the relationship between the acid dissociation constants and structure in drug design studies is important [6]. It also provides useful information about tautomeric equilibria [7,8], solvent-solute interactions [9] etc.Various methods have been developed for the measurement of dissociation constants, such as potentiometry including pH metry [10] spectrophotometry [11], conductometry [12], solubility measurements [13], cryoscopy [14], measurements of the rates of acid catalysed hydrolysis of esters [15], measurement of the relative distribution of an acid between two immiscible solvents [16], dissociation constant by capillary electrophoresis [17], NMR methods [18], feedbackbased flow radiometry [19], interfacial Fourier transform infrared spectroscopy [20], etc. Further, in last few years dissociation constant of many substances such as[21-27] have been studied by various workers.In the present work, the dissociation constant of tetrahydropyrimidine compounds have studied in N, N- dimethyl formamide at $303.15 \mathrm{~K}$.

\section{Experimental}

The Synthesized tetrahydropyrimidine derivatives are recrystallized. Figure 1 shows general structure of synthesized compounds.<smiles>N#Cc1c(N)nc(S)nc1-c1ccccc1</smiles>

Figure 1: General structure for tetrahydropyrimidine derivative.

Where $\mathrm{R}$ is:

SM-1: 4-OH, 3-OCH $-\mathrm{C}_{6} \mathrm{H}_{4} ; \mathrm{SM}-2$ : 4-OCH${ }_{3}-\mathrm{C}_{6} \mathrm{H}_{4} ; \mathrm{SM}-3$ : $4-\mathrm{OH}-\mathrm{C}_{6} \mathrm{H}_{4} ; \mathrm{SM}-4: 4-\mathrm{Cl}_{6} \mathrm{C}_{6}$;

SM-5: 3-Cl- $\mathrm{C}_{6} \mathrm{H}_{4} ; \mathrm{SM}-6$ : 4-F-C $\mathrm{C}_{6} \mathrm{H}_{4} ; \mathrm{SM}-7$ : 3-NO $\mathrm{NO}_{2}-\mathrm{C}_{6} \mathrm{H}_{4} ; \mathrm{SM}-8$ : $-\mathrm{C}_{6} \mathrm{H}_{5} ; \mathrm{SM}-9: \mathrm{C}_{4} \mathrm{H}_{3} \mathrm{O}$;

SM-10: $-\mathrm{CH}=\mathrm{CH}-\mathrm{C}_{6} \mathrm{H}_{5}$.

\section{Measurement}

For the dissociation study, all the chemicals used were of B.D.H Analar grade. All the solutions used for the titration are prepared 
using Mili-Q water. For the titration, different solutions of different concentrations were prepared. i.e.,nitricacid $(1.0 \mathrm{M})$, sodium hydroxide $(0.5 \mathrm{M})$, sodium nitrates $(1.0 \mathrm{M})$. The Solutions of all the compounds were perepared in DMF and of $0.1 \mathrm{M}$ concentration. Nitric acid and sodium hydroxide were standardized by titrating with $0.1 \mathrm{~N} \mathrm{NaOH}$ and $0.05 \mathrm{M}$ succinic acid solution respectively. The buffer solutions used for the calibration of $\mathrm{pH}$ meter were 0.05 $\mathrm{M}$ potassium hydrogen phthalate and $0.01 \mathrm{M}$ Borax buffer.Calvin Bjerrum method [28] is used for the determination of dissociation constant. For this, two sets of mixtures were prepared for titration.

First set of solution contains $2 \mathrm{ml} \mathrm{HNO}_{3}+4 \mathrm{ml}$ water +30 $\mathrm{ml} \mathrm{DMF}+4.0 \mathrm{ml} \mathrm{NaNO}$ and second set of solution contains $2 \mathrm{ml}$ $\mathrm{HNO}_{3}+4 \mathrm{ml}$ water $+28 \mathrm{ml} \mathrm{DMF}+2.0 \mathrm{ml}$ compound solution + $4.0 \mathrm{ml} \mathrm{NaNO}$. The total volume of each solution was $40.0 \mathrm{ml}$ and dimethylformamide:water ratio was 60:40 (v/v).The abovementioned solutions were allowed to attain a constant temperature (303.15 K) and then titrated against standard $\mathrm{NaOH}$ solution under an inert atmosphere of nitrogen.A systronic pH meter (Model No. EQ 664) was used for the $\mathrm{pH}$ determination. The systronic glass electrode and a saturated calomel electrode were used as indicator and reference electrodes respectively. Before operation, the glass electrode was immersed in $0.1 \mathrm{M} \mathrm{HCl}$ for twenty minutes. Then, it was washed thoroughly with distilled water.Before measurement, the $\mathrm{pH}$ meter was calibrated with buffer solution of known $\mathrm{pH}$.

\section{Results and Discussion}

From the above two titrations, two titration curves were obtained for each compound solution. From these curves, the average number of protons associated with compound ( ) can be calculated by Irring and Rossotti equation [29].

$$
\overline{n_{H}}=Y-\left\{\left(V^{\prime \prime}-V^{\prime}\right)\left(N^{0}+E^{0}\right)\right\} /\left\{\left(V^{0}+V^{\prime}\right) T_{L}^{0}\right\}
$$

WhereY is the number of displaceable protons per compound molecule. V' and V" are the volume of alkali required at the same $\mathrm{pH}$ for both acid and compound titration curves respectively. $\mathrm{V}^{0}$ is the initial volume of the test solution. $\mathrm{N}^{0}, \mathrm{E}^{0}$ and $\mathrm{T}^{0}$ Lare the initial concentration of the alkali, acid and compound respectively.For SM 1 and SM 3, value of $Y$ is 2 . Whereas for other compounds, $Y$ is equal to one.

For all the compounds except SM-1 and SM-3 $\overline{n_{H}}$ values are in between zero and one. For SM-1 and SM-3, nHvalue extends over the range from 0 to 2 indicating two dissociation steps. The values at $=0.5$ were evaluated for each systemexcept SM-1 and SM-3. For these two compounds, $p K_{1}^{H}$ and $p K_{2}^{H}$ were calculated at $\overline{n_{H}}=0.5$ and $\overline{n_{H}}=1.5$. Figure 2 shows variation of $\overline{n_{H}}$ with pH (B) for SM-1 and SM-2.

Table 1: The $\log \mathrm{pK}^{\mathrm{H}}$ values for all the studied compounds calculated by different Methods.

\begin{tabular}{|c|c|c|c|c|c|}
\hline \multirow[b]{2}{*}{ Compounds } & \multicolumn{2}{|c|}{$\log \mathrm{pK}_{1}{ }^{\mathrm{H}}$} & \multirow[t]{2}{*}{ Compounds } & \multicolumn{2}{|c|}{$\log \mathrm{pK}_{1}^{\mathrm{H}}$} \\
\hline & $\begin{array}{c}\text { Half-integral } \\
\text { Method }\end{array}$ & $\begin{array}{l}\text { Average } \\
\text { Method }\end{array}$ & & $\begin{array}{c}\text { Half-integral } \\
\text { method }\end{array}$ & $\begin{array}{l}\text { Average } \\
\text { method }\end{array}$ \\
\hline SM-1 & $\begin{array}{c}5.50\left(\mathrm{n}_{\mathrm{H}}=1.5\right) \\
11.50\left(\mathrm{n}_{\mathrm{H}}=0.5\right)\end{array}$ & $\begin{array}{l}5.83\left(\mathrm{n}_{\mathrm{H}}=1.5\right) \\
11.02\left(\mathrm{n}_{\mathrm{H}}=0.5\right)\end{array}$ & SM- 6 & 5.5 & 5.53 \\
\hline
\end{tabular}

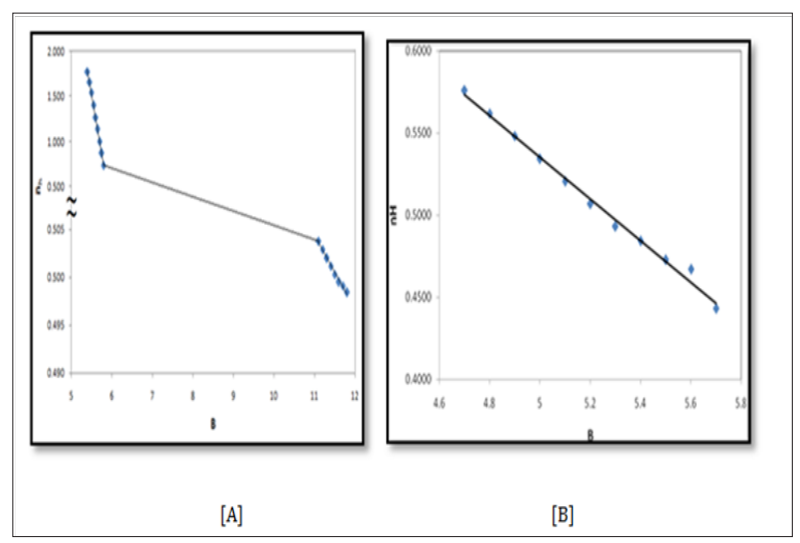

Figure 2: The plot of $\mathrm{n}_{\mathrm{H}}$ against $\mathrm{pH}(\mathrm{B})$ for [A] SM-1 and [B] SM-2.

Further, the $\log \bar{n}_{H} /\left(1-\bar{n}_{H}\right)$ values are plotted against $\mathrm{pH}$ (B) for SM-1 is shown in Figure 3. The plot is a straight line from which $\log p K_{1}^{H}$ values were calculated at several $\mathrm{pH}$ (B) values, by the following equation:

$$
\log p K_{1}^{H}=B+\log \bar{n}_{H} /\left(1-\bar{n}_{H}\right) \ldots
$$

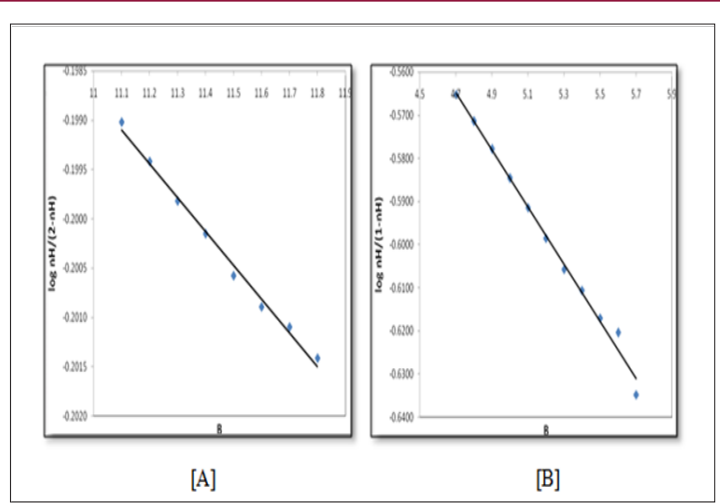

Figure 3: The plot of $\log \mathrm{nH} /(2-\mathrm{nH})$ against $\mathrm{pH}(\mathrm{B})$ for [A] SM-1 and $\log \mathrm{nH} /(1-\mathrm{nH})$ in against $\mathrm{pH}$ (B) for SM-2.

The average pk1H value is also reported in Table 1.For all compounds. It is evident from tables that these pk1Hvalues are in agreement with that obtained by the Figure 2. i.e., at $n_{H}=0.5$.

For SM-1 and SM-3, for all the points below $\overline{n_{H}}=1$, the following equation was used.

$$
\log p k_{1}^{H}=B+\log \bar{n}_{H} /\left(\bar{n}_{H}-1\right)
$$
$\overline{n_{H}}=1$, the equation used was:

Whereas for all the points above $\overline{n_{H}}=1$, th
$\log p k_{1}^{H}=B+\log \left[\left(\bar{n}_{H}-1\right) /\left(2-\bar{n}_{H}\right) \ldots \ldots \ldots \ldots \ldots \ldots . . . . .(4)\right.$ 


\begin{tabular}{|c|c|c|c|c|c|}
\hline SM-2 & 5.2 & 5.22 & SM-7 & 6.2 & 6.2 \\
\hline SM-3 & $\begin{array}{c}5.70\left(\mathrm{n}_{\mathrm{H}}=1.5\right) \\
12.20\left(\mathrm{n}_{\mathrm{H}}=0.5\right)\end{array}$ & $\begin{array}{c}5.80\left(\mathrm{n}_{\mathrm{H}}=1.5\right) \\
11.78\left(\mathrm{n}_{\mathrm{H}}=0.5\right)\end{array}$ & SM-8 & 6.4 & 6.44 \\
\hline SM-4 & 5.3 & 5.26 & SM-9 & 6.4 & 6.38 \\
\hline SM-5 & 5 & 5.01 & SM-10 & 6.3 \\
\hline
\end{tabular}

From the various values of $\log p K_{1}^{H}$ (or $\log p K_{2}^{H}$ ) calculated for a system, the average value was calculated. The values of $\log p K_{1}^{H}$ and $\log p K_{2}^{H}$ calculated by these two methods i.e., half-integral method and average method are given in Table 1. It is observed that in most of the systems, the calculated values by these two methods are in good agreement.

Out of all systems studied, SM-1 and SM-3 are of $\mathrm{H}_{2} \mathrm{~L}$ type whereas others are of HL type. Table 1 shows that the dissociation or acidic constant depends on the type of substituent groups present in the compound. Different groups interact differently with the solvent, which affect their dissociation.Comparison of $p K_{1}^{H}$ values of compounds shows that, SM-5 is more acidic which contains m-chloro group. However, SM-8 is most basic which contains phenyl ring without substitution. SM-1 and SM-3 both contain hydroxyl groups at para positions. But, SM-1 is found to be more acidic than SM-3. From these results, it is concluded that different compounds exhibit different dissociation constant which also depends upon the type and position of substituent group.

\section{References}

1. M Meloun, S Bordovska, A Vrana (2007) The thermodynamic dissociation constants of the anticancer drugs camptothecine, 7-ethyl-10-hydroxycamptothecine, 10-hydroxycamptothecine and 7-ethylcamptothecine by the least-squares nonlinear regression of multiwavelength spectrophotometric $\mathrm{pH}$. Anal Chim Acta 584(2): 419432.

2. A Puetuen, G Bereket, E Keskin (1995) Potentiometric titrations of some 2-substituted 5-nitrobenzimidazole derivatives in nonaqueous solvent. J Chem Eng 40(1): 221-224.

3. I Narin, S Sarioglan, B Anilanmert, H Sari (2010) pKadeterminations for montelukast sodium and levodropropizine. J Sol Chem 39(10): 15821588.

4. AH Vlot, WE de Witte, M Danhof, PH van der Graaf, G J van Westen, et al. (2018) Target and Tissue Selectivity Prediction by Integrated Mechanistic Pharmacokinetic-Target Binding and Quantitative Structure Activity Modeling. AAPS journal 20(1): 11.

5. K Roy, P Popelier (2008) Predictive QSPR modelling of acidic dissociation constant (pKa) of phenols in different solvents. J Phys Org Chem 22: 186196.

6. S Senem, A Yüksel, S Nurullah, A Güleren, B Jose (2009) Solvent Effects on pKa values of some substituted sulfonamides in acetonitrile-water binary mixtures by the UV-Spectroscopy method. J Chem Eng. 54(11): 3014-3021.

7. VL Cherginets, OV Demirskaya, TP Rebrova (2004) Potentiometric studyofacid-baseequilibriain the $\{\mathrm{KCl}+\mathrm{LiCl}\}$ eutecticmeltattemperatures in the range (873 to 1073). K J Chem Thermodynamics 36(2): 115-120.

8. A Doan, E Kilic (2007) Tautomeric and microscopic protonation equilibria of some $\alpha$-amino acids. Anal Biochem 365(1): 7-13.

9. M Taha (2004) Thermodynamic study of the second-stage dissociation of N,N-bis-(2- hydroxyethyl) glycine (bicine) in water at different ionic strength and different solvent mixtures. Annali di Chimica 94(12): 971978.

10. HS Harmed, BB Owen (1958) The Physical Chemistry of Electrolytic Solutions, Reinhold, New York, USA.

11. M Meloun, D Burkonova, T Syrovy, A Vrana (2003) Thermodynamic dissociation constants of silychristin, silybinin, silydianin and mycophenolate by the regression analysis of spectrophotometric data. Analytica Chimica Acta 486: 125-141.

12. JD Sterling, MB Shenda (2017) Electro-lyotropic equilibrium and the utility of ion-pair dissociation constants. Colloid and Interface Science Communications 20: 9-11.

13. HA Krebs, JC Speakman (1945) Dissociation constant, solubility, and the $\mathrm{pH}$ value of the solvent. J Chem Soc pp. 593-595.

14. K Gong, Q Fang, S Gu, S Li, Yan (2015) Nonaqueous redox-flow batteries: organic solvents, supporting electrolytes, and redox pairs. Energy \& Environmental Science 8(12): 3515-3530.

15. HM Dawson, GV Hall, A Key (1928) Acid and salt effects in catalysed reactions-Variation of the catalytic activity of an acid with its concentration and the determination of ionization constants. J Chem Soc 2844-2853.

16. RC Farmer, FJ Warth (1904) The Affinity Constants of the Aniline and its Derivatives. J Chem Soc 85: 1713-1726.

17. JP Mercier, P Morin, Dreux A, Tambute (1998) Determination of weak (2.0-2.5) dissociation constants of non-UV absorbing solutes by capillary electrophoresis. Chromatographia 48(7-8): 529-534.

18. L Fielding (2007) NMR methods for the determination of protein-ligand dissociation constants. Prog in NMR Spect 51: 219-242.

19. H Tanaka, K Aritsuka, T Tachibana, H Chuman, PK Dasgupta (2003) Determination of dissociation constants of weak acids by feedbackbased flow ratiometry. Analytica Chimica Acta 499: 199-204.

20. A Lachenwitzer, N Li, J Lipkowski (2002) Determination of the acid dissociation constant for bisulfate adsorbed at the Pt (111) electrode by subtractivelynormalized interfacial Fourier transform infrared spectroscopy. J Electroanal Chem 532: 85-98.

21. SB Fedorov, LA Kudryavtseva, VE Bel'skii, BE Ivanov (1986) Determination of the dissociation constants of micelle-solubilized compounds. KolloidnyiZhur 48: 199-201.

22. H Tamura, R Furuichi (1988) Determination of the dissociation constants of surface hydroxyl groups: application to the characterization of metal oxides. Nipp Kinz Gakk Kai 27: 158-164.

23. I Jano, J Hardcastle, LA Jano, KR Bates, HE McCreary (2001) General equation for determining the dissociation constants of polyprotic acids and bases from additive properties Part IV. Application to potentiometric titration. Anal Chim Acta 428(2): 309-321.

24. I Zuskova, A Novotna, K Vcelakova, B Gas (2006) Determination of limiting mobilities and dissociation constants of 21 amino acids by capillary zone electrophoresis at very low $\mathrm{pH}$. J Chromato B 841(1-2): 129-134.

25. V Solinova, V Kasicka, D Koval, M Cesnek, A Holy (2006) Determination of acid-base dissociation constants of amino-and guanidinopurine nucleotide analogs and related compounds by capillary zone electrophoresis. Electrophoresis 27(5-6): 1006-1019. 
26. UV Dang, TD Nguyen, MC Vuong (2002) Determination of dissociation constant of monoprotic acids from $\mathrm{pH}$ data by simplex algorithm, Tap Chi Phan TichHoa. Ly VaSinh Hoc 7: 31-36 (2002).

27. K Kulig, K Rybicka, B Malawska (2008) Application of RP-TLC technique for the determination of dissociation constants of 1-substituted pyrrolidin-2-one derivatives. Biomed. Chromato 22(11): 1225-1229.
28. J Bjerrum (1941) Metal Ammine Formation in aqueous solution, P Hease and Sons, Copenhagen.

29. H Irving, HS Rossoti (1954) The calculation of formation curves of metal complexes from $\mathrm{pH}$ titration curves in mixed solvents. J Chem Soc 10: 2094.

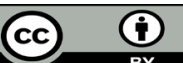

This work is licensed under Creative Commons Attribution 4.0 License

Submission Link: https://biomedres.us/submit-manuscript.php

$\begin{array}{ll}\text { BIOMEDICAL } & \text { Assets of Publishing with us } \\ \text { RESEARCHES } & \text { - Global archiving of articles } \\ & \text { - Immediate, unrestricted online access } \\ & \text { - Rigorous Peer Review Process } \\ & \text { - Authors Retain Copyrights } \\ & \end{array}$

